\title{
PENGARUH METODE LATIHAN DRILL DAN ALLEY RALLY TERHADAP AKURASI GROUNDSTROKES TOP SPIN TENIS LAPANGAN
}

\author{
B. P. Gunarto ${ }^{1}$, I Km. Sukarata. Adnyana ${ }^{2}$ \\ ${ }^{1,2}$ Jurusan Penjaskesrek, Universitas Pendidikan Ganesha \\ Singaraja, Indonesia \\ e-mail: peby.gunarto@undiksha.ac.id, sukarata.adnyana@undiksha.ac.id
}

\begin{abstract}
Abstrak
Tujuan penelitian tentang: (1) pengaruh latihan drill terhadap accuracy groundstroke forehand dan backhand (2) pengaruh latihan alley rally terhadap terhadap accuracy groundstroke forehand dan accuracy groundstroke backhand, dan (3) perbedaan besar pengaruh latihan drill dan alley rally terhadap accuracy groundstroke forehand dan accuracy groundstroke backhand. Penelitian ini adalah penelitian kuantitatif dengan metode ekperimen semu. Populasi penelitian ini adalah atlet putera Club tenis GSTC Singaraja Bali dengan jumlah populasi sebanyak 54 atlet dan Teknik pengambilan sampel dengan purposive random sampling. Hasil penelitian sebagai berikut : (1) pemberian latihan drill berpengaruh signifikan terhadap peningkatan accuracy groundstroke forehand sebesar $86.51 \%$, dan peningkatan accuracy groundstroke backhand sebesar 77,74\%. (2) Pemberian latihan alley rally berpengaruh signifikan terhadap peningkatan accuracy groundstroke forehand sebesar $53,84 \%$, dan peningkatan accuracy groundstroke backhand sebesar 35,13\%. (3) Terdapat perbedaan pengaruh antara latihan drill dan alley rally terhadap accuracy groundstroke forehand dan backhand. Berdasarkan analisis data tersebut, dapat disimpulkan bahwa latihan drill merupakan metode yang lebih baik digunakan untuk meningkatkan accuracy groundstrokes dan kedua metode tersebut berpengaruh signifikan terhadap peningkatan accuracy groundstroke forehand dan backhand.
\end{abstract}

Kata-kata kunci: drill, alley rally, groundstrokes.

\begin{abstract}
The purpose of this study is to analyze about: (1) the effects of exercise drill to the accuracy groundstrokes forehand and accuracy groundstrokes backhand (2) the effects of exercise alley rally against the accuracy groundstrokes forehand and backhand, and (3) the great influence of the exercise drill and alley rally against forehand groundstrokes accuracy and backhand. Population of this research are the son of Club tennis athletes GSTC Singaraja Bali with a total population of 54 athletes and use purposive random sampling. The results of the study as follows: (1) the provision of drill exercises significant influence to increase accuracy of $86.51 \%$ forehand groundstrokes, backhand groundstrokes and increased accuracy of 77.74\%. (2) Provision of training alley rally significant effect on the increase in accuracy of $53.84 \%$ forehand groundstrokes, backhand groundstrokes and increased accuracy of $35.13 \%$. (3) There is a difference between the effects of the exercise drill and alley rally against forehand groundstrokes accuracy and accuracy backhand groundstrokes. Based on
\end{abstract}


analysis of these data, it can be concluded that the exercise drill and alley rally significant effect on the increase in accuracy forehand and backhand groundstrokes.

Keywords : drill, alley rally, groundstrokes.

\section{PENDAHULUAN}

Tenis lapangan adalah salah satu cabang olahraga yang popular di dunia. Permainan yang dimainkan di sebuah lapangan berbentuk persegi panjang yang dibagi menjadi dua oleh sebuah jaring. Sementara itu permainan tenis merupakan permainan yang bersifat individual yang dapat dilakukan dengan cara satu lawan satu atau dua lawan dua, dengan menggunakan raket sebagai alat pemukul dan bola tenis sebagai objek pukul. Sekarang, tenis bukan lagi hanya sekedar untuk mencari kebugaran atau untuk rekreasi, tapi juga sudah dijadikan sebagai alat untuk mencapai prestasi.

Beberapa teknik dasar dalam permainan tenis diantaranya adalah Groundstroke, volley dan service. Groundstroke merupakan memukul dengan forehand maupun backhand setelah bola memantul kearah daerah lawan atau melewati net. Ini adalah bentuk pukulan tenis yang paling sering dilakukan dan paling mudah dipelajari (Jim Brown, 2007). Begitu banyak teknik dasar dalam permainan tenis, tetapi salah satu teknik dasar yang terpenting harus dikuasai oleh atlet tenis adalah groundstroke, karena dalam suatu permainan teknik pukulan tersebut paling sering dilakukan oleh pemain Lucas Loman (2000). Tidak hanya sekedar bisa melakukan, tetapi seorang peamain harus mempunyai ketepatan pukulan yang baik agar bisa mendapatkan poin dan memenangkan pertandingan. "Menurut statistic hanya $25 \%$ seluruh biji kekalahan disebabkan oleh pukulan-pukulan yang benar jitu dan terarah dari lawan, jadi $75 \%$ dari seluruh biji kekalahan disebabkan oleh kesalahan-kesalahan sendiri" (Loman,
2008:79). Bukan hanya dalam pertandingan bahkan dalam latihanpun atlet sering melakukan kesalahan seperti bola menyangkut di net atau bola keluar dari lapangan atau out. Oleh sebab itu atlet harus dilatih ketepatan pukulannya agar atlet mempunyai pukulan yang jitu dan terarah dan meminimalisir kesalahan sendiri. Ketepatan pukulan merupakan sebuah kunci bagi seorang pemain untuk dapat memenangkan pertandingan.

Dari hasil diskusi dengan pelatih

Club Tenis GSTC, beliau mengemukakan bahwa kemampuan anak didiknya dalam mengarahkan bola ke daerah kelemahan lawan sangatlah kurang optimal. Hal ini dikarenakan kurangnya variasi latihan yang diterapkan dalam dalam melakukan teknik groundstroke.

Mengacu pada permasalahan di atas, maka sangatlah penting dalam menerapkan metode latihan yang tepat, sehingga dapat meningkatkan kemampuan atlet, khususnya kemampuan melakukan teknik groundstroke accuracy. Oleh karena itu peneliti mencoba memberi salah satu alternatif pemecahan masalah yaitu dengan menerapkan metode latihan drill dan alley rally. Menurut Van der Meer and Ken Dehart, (1998:26) metode latihan drill dapat meningkatkan penempatan dari groundstroke.

Metode latihan drill merupakan latihan feeding drill atau latihan dengan cara pelatih mengumpankan bola pada atlet dengan arah dan tujuan bola yang ditentukan oleh pelatih David, H.and Rufus, K. (2011:4). Pada metode latihan ini kreativitas pelatih sangatlah diperlukan dalam membuat variasi 
latihan yang disesuaikan dengan kejadian yg nyata saat pertandingan. Dengan metode drill pelatih akan lebih mudah untuk mengoreksi kesalahankesalahan yang di lakukan oleh atlet baik itu dari segi teknik dan hasil pukulan. Kelebihan dari metode latihan drill yaitu atlet akan mempunyai lebih banyak waktu sebelum memukul karena bola yang diumpankan oleh pelatih memantul lebih lambat, sehingga atlet akan lebih mudah untuk mengatur posisi sebelum memukul, baik memukul dengan forehand maupun dengan cara backhand.

Metode latihan alley rally merupakan metode latihan dengan teman yang berada pada lapangan seberang Jim Brown. (2007:50). Latihan ini termasuk latihan live ball. Dikatakan latihan alley rally karena atlet berlatih pada lorong alley atau lorong lapangan ganda dengan melakukan teknik pukulan groundstroke. Pada latihan ini Setiap bola yang dipukul jatuh pada daerah alley teman akan mendapatkan poin 1. Pemain akan berlomba dengan teman yang berada pada lapangan seberang siapa yang lebih dulu mendaptkan poin 11 .

Adapun hasil penelitian yang serupa dengan penelitian ini adalah penelitian M. Jaqfaruhdin Yusuf (2019), menyatakan bahwa Metode latihan drill memberikan pengaruh yang signifikan terhadap peningkatan kemampuan Groundstroke.

Berdasarkan latar belakang masalah yang telah dikemukakan, maka penulis tertarik untuk mengadakan penelitian dengan judul "Pengaruh Metode Latihan Drill dan Alley rally Terhadap Accuracy Groundstroke Forehand topspin dan Backhand topspin Tenis Lapangan.

\section{METODE}

Penelitian ini adalah penelitian eksperimen dengan menggunakan metode eksperimen semu. Teknik pengumpulan data menggunakan Test Groundstroke accuracy menggunakan pedoman international tennis number (2004) . Penelitian dilaksanakan di Kabupaten Buleleng, Kecamatan Buleleng. Populasi dalam penelitian ini sebanyak 54 atlet. Dari jumlah pupulasi yang memenuhi ketentuan-ketentuan untuk menjadi sampel sebanyak 36 atlet. Kemudian dilakukan pretest groundstroke accuracy. Selanjutnya sampel dibentuk kedalam kelompok dengan cara ordinal pairing. Kelompok I sebanyak 12 orang diberi perlakuan latihan drill, kelompok II sebanyak 12 orang diberi perlakuan latihan alley rally, dan kelompok III sebanyak 12 sebagai kelompok kontrol. Analisis statistik yang digunakan adalah uji-t paired sample test dan Analysis of Varians (Anova) dengan taraf signifikan $5 \%$.

Sesuai dengan hipotesis dan jenis penelitian yang digunakan dalam penelitian ini, maka analisis statistik yang digunakan adalah uji-t paired sample test dan Analisis of Varians (Anova) dengan taraf signifikansi $5 \%$ menggunakan program Statistical Product and Service Solution (SPSS) 21.0. untuk mengetahui pengaruh latihan drill dan alley rally terhadap akurasi groundstroke forehand dan backhand tenis lapangan.

Untuk menjawab hipotesis yang telah diajukan, maka uji analisis yang dipergunakan dalam penelitian ini adalah uji beda rerata (uji beda mean) dengan menggunakan analisis uji-t paired t-test. Nilai yang digunakan dalam penghitungan uji-t paired t-test adalah nilai pretest dan posttest dari masing-masing kelompok (kelompok I, kelompok II, dan kelompok III), dengan penyajian datanya hasil perhitungan ujit paired $t$-test adalah sebagai berikut: 
Tabel 1. Uji Beda rerata sampel

\begin{tabular}{lccccc}
\hline \multicolumn{2}{l}{$\begin{array}{l}\text { Accuracy groundstroke } \\
\text { Forehand dan backhand }\end{array}$} & & Mean & Sig.(2-Tailed) & Keterangan \\
\hline $\begin{array}{l}\text { Kelompok I } \\
\text { Drill }\end{array}$ & $\begin{array}{c}\text { Posttest- } \\
\text { Pretest }\end{array}$ & $\begin{array}{l}\text { Forehand } \\
\text { Backhand }\end{array}$ & 32,083 & 0,00 & Ho ditolak \\
Kelompok II & Posttest- & Forehand & 19,833 & 0,00 & Ho ditolak \\
Alley Rally & Pretest & Backhand & 14,750 & 0,00 & Ho ditolak \\
Kelompok III & Posttest- & Forehand & 3,417 & 0,00 & Ho ditolak \\
Kontrol & Pretest & Backhand & 1,500 & 0,00 & Ho ditolak \\
& & & & & Ho ditolak \\
\hline
\end{tabular}

Hasil perhitungan uji-t paired $t$ test pada pemberian latihan drill dengan melihat nilai Sig. (2-tailed) 0,00, Maka dapat disimpulkan bahwa $H o$ ditolak dan $\mathrm{Ha}$ diterima karena nilai Sig. 0,00 < nilai $\alpha=0,05$. Dengan kata lain terdapat pengaruh sebesar 32,083 dari pemberian latihan drill terhadap accuracy groundstroke forehand pada atlet tenis GSTC Singaraja.

Hasil perhitungan uji-t paired $t$ test pada pemberian latihan alley rally dengan melihat nilai Sig. (2-tailed) 0,00, Maka dapat disimpulkan bahwa $\mathrm{Ho}$ ditolak dan $\mathrm{Ha}$ diterima karena nilai Sig. $0,00<$ nilai $\alpha=0,05$. Dengan kata lain terdapat pengaruh sebesar 19,833 dari pemberian latihan alley rally terhadap accuracy groundstroke forehand pada atlet tenis GSTC Singaraja.

Hasil perhitungan uji-t paired ttest pada pemberian latihan drill dengan melihat nilai Sig. (2-tailed) 0,00, Maka dapat disimpulkan bahwa Ho ditolak dan Ha diterima karena nilai Sig. 0,00 < nilai $\alpha=0,05$. Dengan kata lain terdapat pengaruh sebesar 21,833 dari pemberian latihan drill terhadap accuracy groundstroke backhand pada atlet tenis GSTC Singaraja
Hasil perhitungan uji-t paired t-test pada pemberian latihan alley rally dengan melihat nilai Sig. (2-tailed) 0,00, Maka dapat disimpulkan bahwa Ho ditolak dan Ha diterima karena nilai Sig. 0,00 < nilai $\alpha=0,05$. Dengan kata lain terdapat pengaruh yang signifikan sebesar 14,750 dari pemberian latihan alley rally terhadap accuracy groundstroke backhand pada atlet tenis GSTC Singaraja.

\section{HASIL DAN PEMBAHASAN}

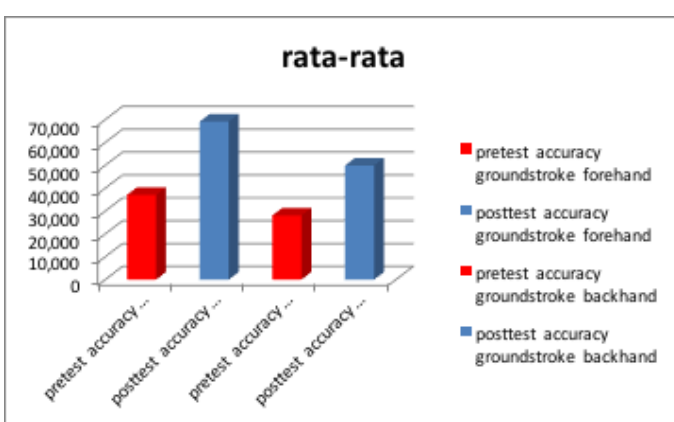

Gambar 1. Data hasil latihan drill

Berdasarkan hasil pengukuran dalam tabel 2 di atas pada kelompok I dapat dilihat bahwa terdapat sebuah peningkatan nilai rerata antara pretest dan posttest pada variabel dependent. Hal ini terbukti dari nilai rerata posttest dan nilai rerata pretest. Dimana dapat di lihat bahwa nilai rerata untuk accuracy 
groundstroke forehand hasil pengukuran posttest $(69,166)$, ini terlihat lebih tinggi dibanding dengan hasil pengukuran pretest $(37,083)$ dan accuracy groundstroke backhand dari hasil pengukuran posttest $(49,916)$, ini terlihat lebih tinggi dibanding dengan hasil pengukuran pretest sebesar (28,083). Dalam pemberian treatment pada kelompok I dapat meningkatkan accuracy groundstroke forehand dan accuracy groundstroke backhand.

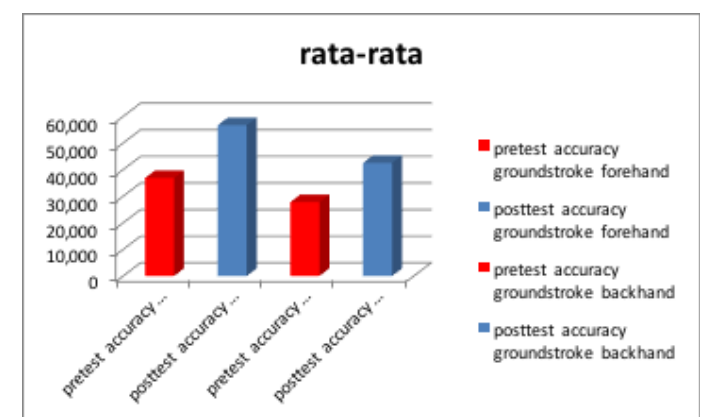

Gambar 2. Data hasil alley rally
Berdasarkan hasil pengukuran dalam tabel 3 di atas pada kelompok II dapat dilihat bahwa terdapat sebuah peningkatan nilai rerata antara pretest dan posttest pada variabel dependent. Dimana dapat di lihat bahwa nilai rerata untuk accuracy groundstroke forehand hasil pengukuran posttest $(56,666)$, ini terlihat lebih tinggi dibanding dengan hasil pengukuran pretest $(36,833)$ dan accuracy groundstroke backhand dari hasil pengukuran posttest $(42,5)$, ini terlihat lebih tinggi dibanding dengan hasil pengukuran pretest sebesar (27,75). Dalam pemberian treatment pada kelompok II dapat meningkatkan accuracy groundstroke forehand dan accuracy groundstroke backhand.

Tabel 2. Pengujian Hipotesis Groundstroke Forehand

\begin{tabular}{lrlll}
\hline \multicolumn{2}{l}{ Accuracy groundstroke forehand } & Mean & $\begin{array}{l}\text { Sig } \\
\text { tailed) }\end{array}$ & (2- keterangan \\
\hline $\begin{array}{l}\text { Kelompok I } \\
\text { drill }\end{array}$ & Posttest-pretest forehand & 32,083 & 0,00 & Ho ditolak \\
$\begin{array}{l}\text { Kelompok } \\
\text { alley rally }\end{array}$ & Posttest-pretest forehand & 19,833 & 0,00 & Ho ditolak \\
$\begin{array}{l}\text { Kelompok III } \\
\text { Kontrol }\end{array}$ & Posttest-pretest forehand & 3,417 & 0,00 & Ho ditolak \\
\hline
\end{tabular}

Berdasakan Hasil perhitungan uji-t paired t-test pada pemberian latihan drill dengan melihat nilai Sig. (2-tailed) 0,00, Maka dapat disimpulkan bahwa $\mathrm{Ho}$ ditolak dan $\mathrm{Ha}$ diterima karena nilai Sig. $0,00<$ nilai $\alpha=0,05$. Dengan kata lain terdapat pengaruh sebesar 32,083 dari pemberian latihan drill terhadap accuracy groundstroke forehand dan Hasil perhitungan uji-t paired t-test pada pemberian latihan alley rally dengan melihat nilai Sig. (2tailed) 0,00, Maka dapat disimpulkan bahwa $\mathrm{Ho}$ ditolak dan $\mathrm{Ha}$ diterima karena nilai Sig. $0,00<$ nilai $\alpha=0,05$. Dengan kata lain terdapat pengaruh sebesar 19,833 dari pemberian latihan alley rally terhadap accuracy groundstroke forehand. 
Tabel 3. Pengujian hipotesis Groundstroke Backhand

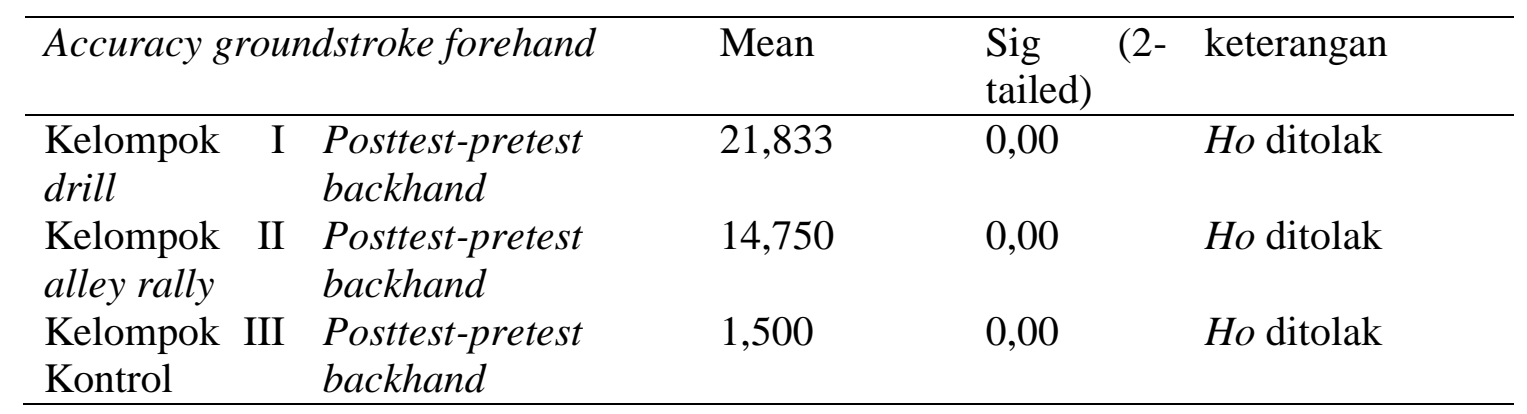

Hasil perhitungan uji-t paired $t$ test pada pemberian latihan drill dengan melihat nilai Sig. (2-tailed) 0,00, Maka dapat disimpulkan bahwa $\mathrm{Ho}$ ditolak dan Ha diterima karena nilai Sig. 0,00 < nilai $\alpha=0,05$. Dengan kata lain terdapat pengaruh sebesar 21,833 dari pemberian latihan drill terhadap accuracy groundstroke backhand dan pada Kelompok II (Alley Rally) Hasil perhitungan uji-t paired t-test pada pemberian latihan alley rally dengan melihat nilai Sig. (2-tailed) 0,00, Maka dapat disimpulkan bahwa $H o$ ditolak dan $\mathrm{Ha}$ diterima karena nilai Sig. 0,00 < nilai $\alpha=0,05$. Dengan kata lain terdapat pengaruh yang signifikan sebesar 14,750 dari pemberian latihan alley rally terhadap accuracy groundstroke backhand.

\section{PEMBAHASAN}

1. Perlakuan dengan Latihan Drill Berdasarkan hasil pengujian hipótesis, ternyata latihan drill memiliki pengaruh yang signifikan terhadap peningkatan accuracy groundstroke forehand yaitu rata-rata peningkatannya sebesar 32,08. Latihan drill juga memiliki pengaruh yang signifikan terhadap peningkatan accuracy groundstroke backhand yaitu rata-rata peningkatannya sebesar 21,83. Dengan demikian dapat disimpulkan bahwa latihan drill mempunyai pengaruh yang signifikan terhadap variabel dependen accuracy groundstroke forehand dan accuracy groundstroke backhand.
Namun pengaruh yang paling signifikan yang diberikan oleh latihan drill adalah accuracy groundstroke forehand. . Hal ini dikarenakan pada saat pemberian latihan ini menggunakan mesin drill atlet lebih diuntungkan oleh dua hal yaitu yang pertama pada kecepatan bola yang datang dari lontaran mesin drill dan yang kedua pada sudut memukul yang menyebabkan atlet lebih mudah menempatkan posisi untuk memukul sehingga mempermudah untuk mengarahkan bola pada arah yang di inginkan. Cyril, B (2016).

\section{Perlakuan dengan Latihan Alley Rally}

Berdasarkan hasil pengujian hipotesis, ternyata perlakuan dengan latihan alley rally memiliki pengaruh yang signifikan terhadap peningkatan accuracy groundstroke forehand yaitu rata-rata peningkatannya sebesar 19,83. Latihan alley rally juga memiliki pengaruh yang signifikan terhadap peningkatan accuracy groundstroke backhand yaitu rata-rata peningkatannya sebesar 14,75. Dengan demikian dapat disimpulkan bahwa latihan alley rally mempunyai pengaruh yang signifikan terhadap variable dependen accuracy groundstroke forehand dan accuracy groundstroke backhand, namun pengaruh yang paling signifikan diberikan oleh latihan alley rally adalah accuracy groundstroke forehand. Hal ini juga dikuatkan oleh 
pendapat Van der meer (1998) bahwa latihan alley rally dapat meningkatkan arah penempatan bola pada groundstroke Hal ini dikarenakan pada penerapan metode latihan lebih menyerupai pada situasi pertandingan karena bola yang diterima oleh atlet saat latihan sama dengan apa yang diterima saat bertanding.

3. Perbedaan Pengaruh Latihan Terhadap Groundstroke Forehand Perbedaan pengaruh latihan drill, alley rally dan kontrol terhadap accuracy groundstroke forehand. Berdasarkan hasil pengujian hipotesis, ternyata perlakuan dengan latihan drill memiliki pengaruh yang signifikan terhadap peningkatan accuracy groundstroke forehand .Hal ini dikarenakan latihan drill lebih memudahkan atlet dalam memperbaiki kesalahan- kesalahan teknik memukul, yaitu ketika atlet salah dalam mengambil posisi untuk memukul pada repetisi berikutnya atlet akan lebih bebas untuk mengambil sudut memukul karena jatuhnya bola yang datang dari mesin drill tidak berubah ubah atau konsisten, Cyril, B (2016). Dari penjelasan tersebut, maka dapat disimpulkan bahwa latihan drill berpengaruh terhadap accuracy groundstroke forehand daripada latihan alley rally dan kontrol. Dilihat dari rata-rata peningkatannya yaitu latihan drill rata-rata peningkatannya sebesar 32,08 dibandingkan dengan peningkatan dari latihan alley rally yaitu sebesar 19,08 dan peningkatan dari kelompok kontrol 4,25.

\section{Perbedaan Pengaruh Latihan Terhadap Groundstroke Forehand}

Berdasarkan hasil pengujian hipotesis, ternyata perlakuan dengan latihan drill memiliki pengaruh yang signifikan terhadap peningkatan accuracy groundstroke backhand. Hal ini disebabkan latihan alley rally lebih susah diterima oleh atlet ketika atlet akan memperbaiki teknik atau accuracy pukulan, karena bola yang datang pada atlet bersifat realistis seperti bola yang diterima waktu bertanding. Oleh sebab itu atlet akan lebih susah untuk mengoreksi dan memperbaiki kesalahan teknik yang dialaminya, David \& Rufus, K (2011). Dari penjelasan tersebut, maka dapat disimpulkan bahwa latihan drill lebih berpengaruh signifikan terhadap peningkatan accuracy groundstroke backhand daripada latihan alley rally dan kelompok kontrol dilihat dari ratarata peningkatannya yaitu latihan drill rata-rata peningkatannya sebesar 21,83 dibandingkan dengan latihan alley rally yaitu sebesar 14,75 dan peningkatan dari kelompok kontrol sebesar 9,00.

\section{SIMPULAN DAN SARAN}

Berdasarkan hasil penelitian dan pembahasan yang telah diuraikan maka kesimpulan dari penelitian ini sebagai berikut : Program latihan drill dapat meningkatkan accuracy groundstroke forehand dan accuracy groundstroke backhand. Program latihan alley rally dapat meningkatkan accuracy groundstroke forehand dan accuracy groundstroke backhand. Program latihan drill berpengaruh lebih besar daripada latihan alley rally terhadap accuracy groundstroke forehand dan accuracy groundstroke backhand.

Berdasarkan hasil penelitian, adapun saran yang ingin disampaikan kepada atlet dan pelatih, diantaranya yaitu : Para atlet dan pelatih sebaiknya menerapkan program latihan drill karena telah terbukti memberikan hasil yang lebih baik daripada program latihan alley rally terhadap peningkatan accuracy groundstroke forehand dan 
backhand. Pemberian program latihan harus memperhatikan prinsip-prinsip sesuai dengan karakteristik dan tingkatan terutama dalam penentuan set dan repetisi agar tercapai hasil yang maksimal tanpa mengalami overtraining.

\section{DAFTAR PUSTAKA}

Cyril, B., Grégoire, M., and Laurent, S., 2016. "Accuracy and Reliability of a New Tennis Ball Machine". CJournal of Sports Science and Medicine (2016) 15, 263-267.

David, H and Rufus K, 2011. Global Tennis Coaching. www.ebookAuthorAcademy.com

International Tennis Number. 2004. Testing Procedure. International
Tennis Federation (diunduh tanggal 23 September 2015).

Jim Brown. 2007. Tenis Tingkat Pemula. Jakarta: PT Raja Grafindo Persada.

Lardner, Rex. 2013. Fundamental Tenis. Semarang : Dahara Prize.

Loman L. (2000). Petunjuk Praktis Bermain Tenis. Bandung: Angkasa

The Lawn Tennis Association. 2010. British Tennis. A \& C Black. 